\title{
Spasmodic torticollis: a combined clinical study
}

\author{
W. B. MATTHEWS, PATR ICK BEASLE Y ${ }^{1}$, \\ W I L L I A M P A R R Y - J O NES, A N D G. GAR L A N D \\ From the University Department of Clinical Neurology, Churchill Hospital, \\ and the Department of Psychiatry, The Warneford Hospital, Oxford
}

SUMMARY The prognosis in 30 patients with spasmodic torticollis proved to be unexpectedly bad, only one patient making a full and sustained recovery. Investigation did not confirm previously reported reflex influences on the degree of spasm. Detailed otological investigation did not suggest that spasmodic torticollis originates in vestibular dysfunction. Psychological assessment of the patients showed no deviation from normal in premorbid personality but confirmed the severe adverse effects of the condition.

Spasmodic torticollis remains an essentially intractable and disabling condition of unknown cause. Opinion is still divided on whether it is an organic or psychogenic disease or whether two forms exist (Meares, 1971a). In this study particular attention has been paid to this aspect-to the natural history and relation to other forms of neurological disorder, the relevance of vestibular disease (Svien and Cody, 1969), the relation to thyrotoxicosis (Gilbert, 1971), and the effect of movement and other stimuli on the degree of spasm (Podivinsky, 1968).

\section{Clinical material}

In 1971 an attempt was made to trace all patients diagnosed as having spasmodic torticollis in the index of the Radcliffe Infirmary since 1954. Of these 37 patients seven could not be traced and two are known to have died. Eight patients either did not wish to be seen or their general practitioners advised against further interest in their complaint. Of these, four were known still to have torticollis in 1971 and four claimed to have recovered. Data from these eight patients have not been included in the survey, largely because of the difficulty in assessing the real extent of recovery. Detailed study was limited to the 20 patients traced from the diagnostic index and personally examined, and to 10 further patients seen in clinical practice between 1971 and 1973.

${ }^{1}$ Present address: Royal Devon and Exeter Hospital, Exeter.

Address for reprint requests: Professor W. B. Matthews, University of Oxford, Department of Clinical Neurology, The Churchill Hospital, Headington, Oxford OX3, 7LJ, England.

Accepted 26 January 1978

\section{Methods}

A detailed medical history and examination were recorded. Investigations carried out on a proportion of patients included radiographs of the skull and cervical spine, and tests of thyroid function (protein-bound iodine (PBI) in 1971). In 1976 all patients seen in the original survey were again followed up either by interview or postal enquiry.

The EMG was recorded either on an ink-writing EEG machine from surface electrodes over the sternomastoid, trapezius, and deep cervical muscles, or from the sternomastoid muscles using a two-channel Medelec electromyograph. The effects of eye closure, lifting a weight with either hand, cutaneous stimulation on the neck and face, and of the patient's own "antagonistic gesture" were observed.

Routine otological examination was carried out, and, in addition, electronystagmography (ENG) was recorded from electrodes at the outer canthus of each eye with a central reference electrode on the forehead. Spontaneous nystagmus was sought with the eyes open and closed, and with gaze directed ahead and to either side. The effect of passive neck torsion with the patient seated was also examined. Postural nystagmus was sought in the supine, prone, and both lateral positions. Caloric labyrinthine stimulation, either single iemperature cold stimulation or bithermal stimulation was carried out as follows:
1. left ear
2. right ear $\}$ at $30^{\circ} \mathrm{C}$
3. left ear
4. right ear
at $44^{\circ} \mathrm{C}$

with the head raised $30^{\circ}$ from the horizontal and 
the eyes closed. The number of beats of nystagmus in the period 60-90 seconds after the beginning of stimulation was recorded and counted, and used in the calculation of preponderance (Hinchcliffe, 1968). Labyrinthine preponderance (LP) was calculated according to Jongkees' formula (Jongkees and Philipszoon, 1963):

$$
\mathrm{LP}=\frac{(1+3)-(2+4)}{1+2+3+4} \times 100 \%
$$

For single temperature caloric tests the difference between the two sides was expressed as a percentage of the total response of the two sides.

Directional preponderance of nystagmus (DP) was calculated from Jongkees' formula:

$$
\mathrm{DP}=\frac{(1+4)-(2+3)}{1+2+3+4} \times 100 \%
$$

Values of less than $30 \%$ are not considered as significant deviations from normal.

Psychological and psychiatric investigation was particularly directed towards the assessment, as far as possible, of the premorbid state, the possible relevance of stress to the onset of torticollis, and the psychological and social effects of the chronic disorder. Particular attention was paid to the possibility of detecting a psychogenic group with a better prognosis than that of the presumed organic form of torticollis. Investigations comprised a structured clinical interview with the patient and, whenever possible, with the spouse or closest other person. Special attention was focused on social and marital adjustment, the psychiatric history, and the subject's life situation at the time of the onset of the disorder. Specific investigations included the Eysenck Personality Inventory, form $A$, the Leyton Obsessional Inventory, and the Hostility and Direction of Hostility questionnaire (HDHQ). Married subjects and their spouses completed the Ryle Marital Patterns Test and a simple marital adjustment rating scale.

\section{Results}

Of the 30 patients investigated, nine were male and 21 female. The age of onset is seen in Table 1 .

Table 1 Age of onset

\begin{tabular}{cc}
$\begin{array}{l}\text { Age of onset } \\
(y r)\end{array}$ & Number of patients \\
\hline $0-10$ & 0 \\
$11-20$ & 3 \\
$21-30$ & 3 \\
$31-40$ & 8 \\
$41-50$ & 9 \\
$51-60$ & 6 \\
$61-70$ & 1 \\
Total & 30 \\
\hline
\end{tabular}

There was a marked preponderance in the fourth and fifth decades. In 12 patients the torticollis turned the chin to the right and in 15 to the left. One patient had retrocollis, and in two patients who had sustained more than one episode the direction of turn had altered.

In no patient was a history of epidemic encephalitis obtained, and there was no evidence that torticollis was drug-induced. No patient gave a family history of torticollis or of any form of organic nervous disease other than stroke, with the exception of one patient who had a family history of essential tremor.

In two of the 25 patients $x$-rayed, a congenital anomaly of the cervical spine was seen; in one, spina bifida occulta of $\mathrm{C} 6$ and 7 vertebrae and in the other, fusion of the bodies of C5 and 6 vertebrae. Significant asymmetry of the skull was not detected in any of the 10 patients in whom satisfactory radiographs could be obtained. Thyroid function (PBI) was normal in the nine patients in whom this was examined.

Additional neurological signs were present in six patients. Two patients had dystonic movements of one upper limb, probably developing at the same time as the torticollis but without subsequent progression. One patient had writer's cramp. One patient developed widespread torsion dystonia 24 years after the initial episode of torticollis. One patient had slight signs of Parkinson's disease when first seen with torticollis. One patient had both hereditary essential tremor and a mild infantile hemiparesis. In the remaining 24 patients torticollis was the only neurological abnormality. No association with any systemic disease was recognised.

\section{OUTCOME}

At the time of the survey in 1971-73 only one patient was entirely free of symptoms relevant to spasmodic torticollis. A further four patients were classified as having made a substantial recovery in that no torticollis was present, but these patients were still aware of some abnormality, and found that, under even mild stress, pain and tension would develop in the neck muscles in a manner recognisably related to their original symptoms. Three patients gave a history of complete remission followed by relapse, although, as they were not seen during the symptom-free period, it is not known whether remission was indeed complete. The details of the eight patients in whom substantial or complete remission had occurred at some stage are shown in Table 2 . In general, remission occurred relatively soon after the onset but relapse might occur after many years of free- 
Table 2 Cases with remission

\begin{tabular}{|c|c|c|c|c|c|c|c|c|c|}
\hline \multirow[t]{2}{*}{ Case } & \multirow[t]{2}{*}{ Sex } & \multirow{2}{*}{$\begin{array}{l}\text { Age at } \\
\text { initial } \\
\text { survey } \\
(y r)\end{array}$} & \multirow{2}{*}{$\begin{array}{l}\text { Age at } \\
\text { onset } \\
(y r)\end{array}$} & \multirow{2}{*}{$\begin{array}{l}\text { Duration of } \\
\text { first attack } \\
(y r)\end{array}$} & \multirow{2}{*}{$\begin{array}{l}\text { Age at } \\
\text { relapse } \\
(y r)\end{array}$} & \multirow{2}{*}{$\begin{array}{l}\text { Duration of } \\
\text { relapse } \\
(y r)\end{array}$} & \multicolumn{2}{|l|}{ Results } & \multirow[t]{2}{*}{ Comments } \\
\hline & & & & & & & $1971-73$ & 1976 & \\
\hline 1 & $\mathbf{F}$ & 56 & 41 & $4 / 12$ & - & - & $\mathbf{R c}$ & Rc & \\
\hline 2 & $\mathbf{M}$ & 46 & 35 & 2 & 49 & $2 / 12$ & SRc & SRc & Relapse after initial survey with remission \\
\hline 3 & $\mathbf{F}$ & 26 & 18 & 1 & - & - & SRc & $\mathrm{SRc}$ & \\
\hline 4 & $\mathrm{~F}$ & 52 & 35 & 1 & $\begin{array}{l}37 \\
54\end{array}$ & $\begin{array}{l}3 / 12 \\
4 / 12\end{array}$ & SRc & $\mathrm{SRc}$ & Relapse after initial survey with remission \\
\hline 5 & $\mathbf{F}$ & 57 & 52 & 1 & 61 & $2 \div$ & $\mathrm{SRc}$ & $\mathbf{P}$ & Relapse after initial survey without remission \\
\hline 6 & $\mathbf{M}$ & 47 & 15 & 2 & 38 & $14+$ & $\mathbf{P}$ & $\mathbf{P}$ & Dystonia began with relapse \\
\hline 7 & $\mathrm{~F}$ & 45 & 39 & 4 & 45 & $5+$ & $\mathbf{P}$ & $\mathbf{P}$ & Disabled after surgery \\
\hline 8 & $\mathbf{M}$ & 64 & 39 & 1 & 53 & $13+$ & $\mathbf{P}$ & $\mathbf{P}$ & Writer's cramp \\
\hline
\end{tabular}

$\mathbf{R c}=$ recovery $; \mathbf{S R c}=$ substantial recovery $; \mathbf{P}=$ persistent torticollis

dom. The caution exercised in distinguishing "substantial" from "complete" recovery in the original survey was justified by the further relapse of three of these four patients between 1971 and 1976 , one being left with persistent torticollis.

At the time of the initial survey 22 patients had had persistent torticollis from between a few months to 40 years (Table 3). By 1976 three patients had died of cardiac disease. Torticollis had been present to the end in two of these patients and probably in the third. No necropsy was obtained. In 11 patients the torticollis had not changed but in six there had been significant improvement, although in one of these Parkinson's disease had become increasingly disabling. No patient had recovered.

The type of movement present at the onset, whether jerking or turning, and the presence of

Table 3 Cases with persistent torticollis at the time of the initial survey

\begin{tabular}{|c|c|c|c|c|c|}
\hline Case & Sex & $\begin{array}{l}\text { Age at } \\
\text { survey } \\
(y r)\end{array}$ & $\begin{array}{l}\text { Age at } \\
\text { onset } \\
(y r)\end{array}$ & $\begin{array}{l}1976 \\
\text { Result }\end{array}$ & Comments \\
\hline 9 & $\mathbf{F}$ & 48 & 28 & Unchanged & \\
\hline 10 & $\mathbf{M}$ & 48 & 47 & Unchanged & \\
\hline 11 & $\mathbf{F}$ & 67 & 52 & Unchanged & Dystonia of one arm \\
\hline 12 & $\mathbf{M}$ & 57 & 52 & Died 1974 & \\
\hline 13 & $\mathrm{~F}$ & 64 & 51 & Died 1974 & \\
\hline 14 & $\mathrm{~F}$ & 66 & 49 & Improved & \\
\hline 15 & $\mathbf{M}$ & 46 & 43 & Unchanged & Dystonia of one arm \\
\hline 16 & $\mathbf{M}$ & 59 & 36 & Unchanged & \\
\hline 17 & $F$ & 64 & 24 & Unchanged & \\
\hline 18 & $\mathbf{F}$ & 42 & 37 & Improved & Parkinson's disease \\
\hline 19 & $F$ & 45 & 43 & Unchanged & $\begin{array}{l}\text { Infantile hemiparesis } \\
\text { Essential tremor }\end{array}$ \\
\hline 20 & $\mathbf{F}$ & 63 & 61 & Improved & \\
\hline 21 & $\mathrm{~F}$ & 31 & 29 & Improved & \\
\hline 22 & $\mathrm{~F}$ & 44 & 43 & Unchanged & \\
\hline 23 & $\mathbf{M}$ & 49 & 48 & Unchanged & \\
\hline 24 & $\mathrm{~F}$ & 37 & 36 & Unchanged & \\
\hline 25 & $\mathrm{~F}$ & 37 & 35 & Unchanged & \\
\hline 26 & $\mathrm{~F}$ & 44 & 41 & Improved & \\
\hline 27 & $\mathrm{~F}$ & 53 & 52 & Improved & \\
\hline 28 & $\mathbf{M}$ & 34 & 16 & Unchanged & \\
\hline 29 & $\mathbf{F}$ & 34 & 31 & Improved & \\
\hline 30 & $F$ & 76 & 65 & Died 1974 & \\
\hline
\end{tabular}

pain have been thought to be of prognostic significance (Tibbetts, 1971; Mears, 1971a). Of those who experienced a partial or complete remission the onset was judged, in retrospect, to have been jerking in one, turning in six, and with a fixed posture in one. In those with persistent torticollis the onset was jerking in six, turning in 14 , and with a fixed posture in two. Pain was remembered as being present at the onset in 10 of the 22 with persistent torticollis, and four of the eight in whom remission had occurred.

\section{ELECTROMYOGRAPHY}

This was carried out in 16 patients. The results confirmed the widespread contraction of the neck muscles even when the posture of the head suggested relatively isolated contraction of one sternomastoid muscle. The antagonistic gesture habitually used by each patient to restrain the torticollis was observed to inhibit muscular contraction in five (Fig. 1) and to have no effect in three, but in seven patients, under the condition of the test, spasm was enhanced (Fig. 2). Eye closure had no effect on the spasm in 13 patients, but regularly induced inhibition in one patient (Fig. 3). In another patient, however, eye opening was regularly followed by reduction of spasm.

The effect of lifting a weight with the hand on the same or opposite side to the direction of head turning was recorded, but no consistent results were obtained. In six patients lifting a weight with either hand increased the EMG activity recorded from the neck (Fig. 4a, b), and in three no effect was observed. In three, using the ipsilateral hand increased spasm while use of the contralateral hand resulted in inhibition or had no effect, but in two patients these responses were reversed. In one patient using either hand inhibited spasm of the neck muscles (Fig. 5a, b). Light touch with cotton wool on the side of the neck and face had no recordable effect on spasm in the 10 patients in whom this was examined. 


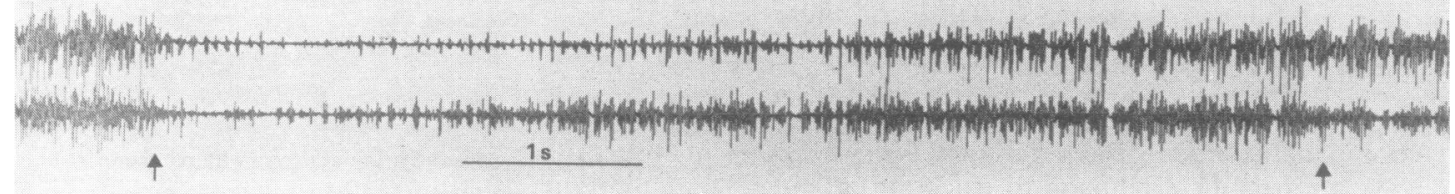

Fig. 1 Surface recordings from right (below) and sternomastoid muscles in case 22 with torticollis to the left. Arrows indicate beginning and ending of the patient's habitual antagonistic gesture of placing the hand on left side of chin.

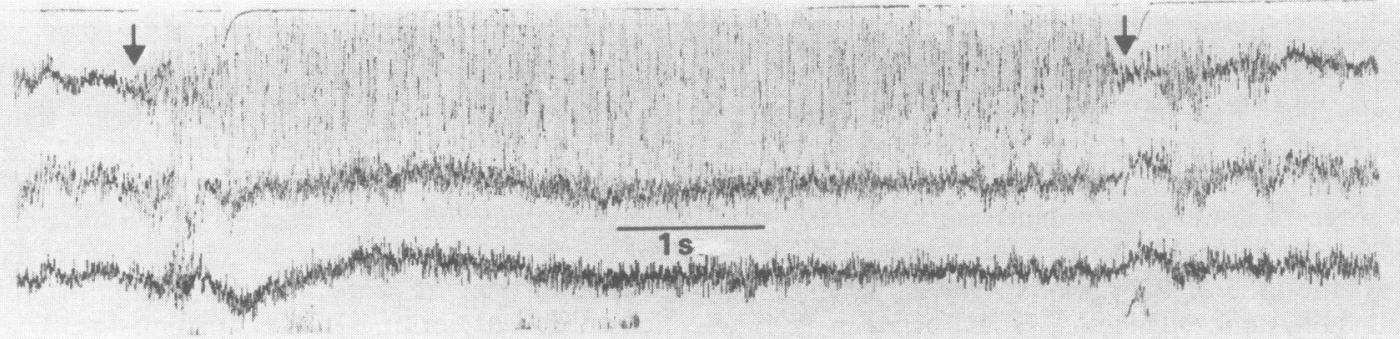

Fig. 2 Surface recordings from right sternomastoid (above), deep cervical muscles and trapezius (below) in case 6 with torticollis to left. Arrows indicate beginning and ending of antagonistic gesture.

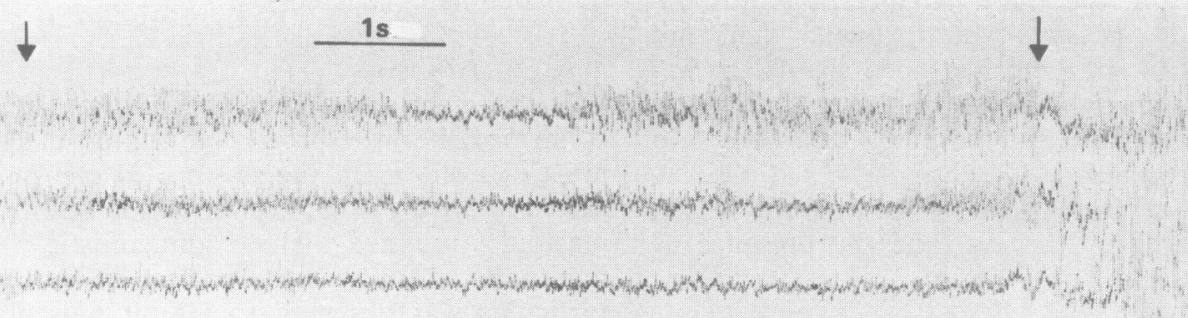

Fig. 3 Electrode placements as in Fig. 2 in case 13 showing the effect of eye closure and subsequent opening indicated by arrows.

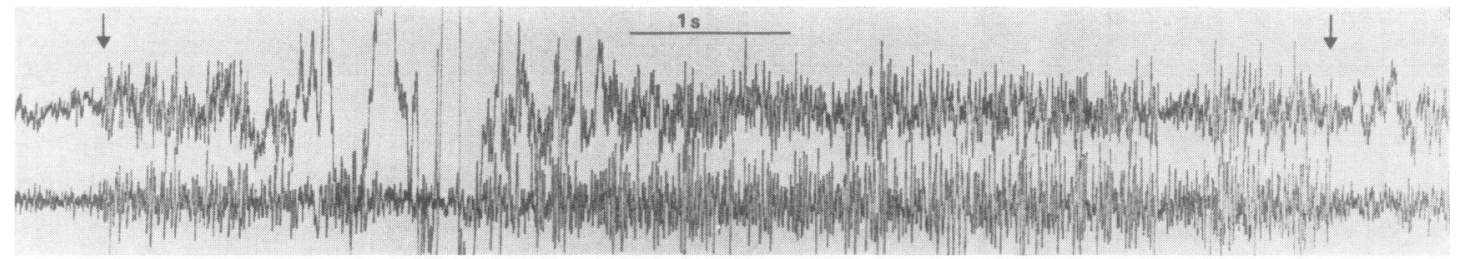

(a)

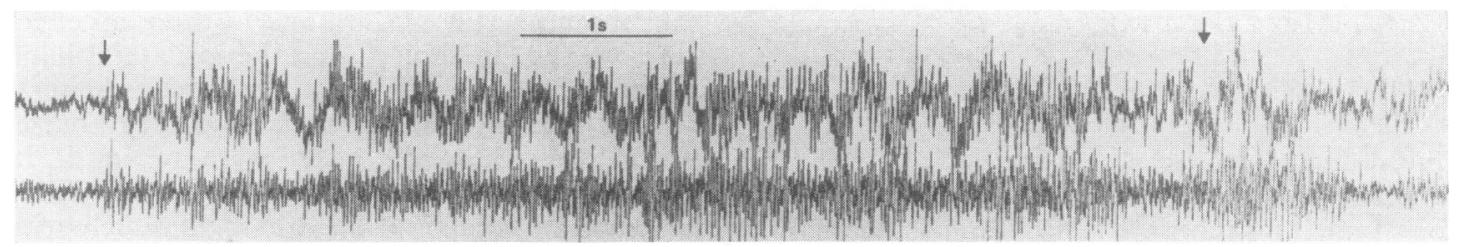

(b)

Fig. 4 Surface recordings from right (above) and left sternomastoids in case 27 showing enhancement of spasm after lifting $a$ weight with the right $(a)$ and left $(b)$ hands. 


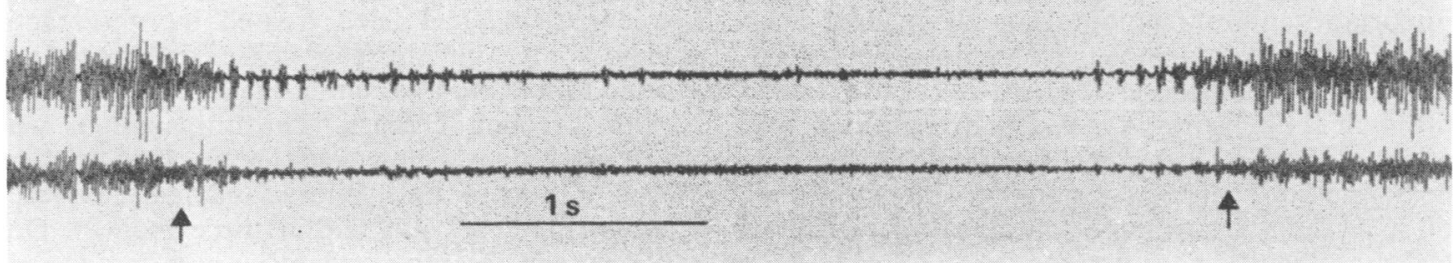

(a)

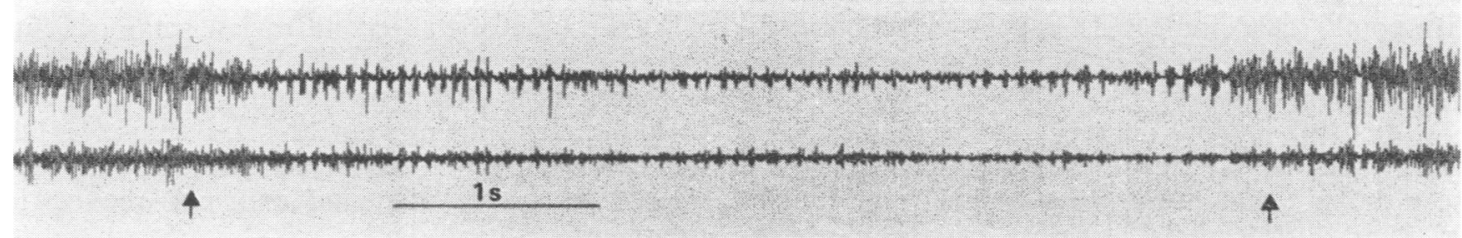

(b)

Fig. 5 Electrode placements as in Fig. 1 in case 22 showing inhibitory effect of lifting a weight with right (a) or left (b) hand.

OTOLOGICAL EXAMINATION (PB)

Sixteen patients were examined, but not all techniques were applied in every case (case numbers refer to Tables 2 and 3 ).

Case 3 had inactive right chronic suppurative otitis media. Pure tone audiometry was normal in cases $28,15,7$, and 10 . There was symmetrical presbyacusis in case 8 and 11 , and case 19 had a bilateral sensorineural deafness around $4 \mathrm{kHz}$ with an audiographic curve characteristic of minor acoustic trauma.

Spontaneous nystagmus with eyes closed was recorded in five of the 15 patients in whom it was sought (cases $4,6,7,8$, and 12). In each case nystagmus was to the right. Neck torsion nystagmus was not elicited in any patient and positional nystagmus only in case 15 in whom it occurred to the left in the supine and left lateral positions.

Six patients were examined by single temperature caloric stimulation and nine by bithermal caloric tests. Assuming a level of significance of $30 \%$, only case 8 showed labyrinthine preponderance at $44 \%$, the left labyrinth being the preponderant and the direction of turning being to the left. In the remaining 15 cases showing minor degrees of labyrinthine preponderance the direction of torticollis was away from the preponderant labyrinth in 11 cases and toward it in three. In no patient was significant directional preponderance of nystagmus found, but in nine cases showing minor degrees of such preponderance it was opposite in direction to the torticollis in eight and in the same direction in one.
PSYCHOLOGICAL AND PSYCHIATRIC EXAMINATION (WLP-J AND GG)

Twenty-nine patients were examined, one being excluded because of severe deafness due to otosclerosis (this patient was not examined otologically). Two patients had received psychiatric treatment at some time before the onset of torticollis, in both cases for depression.

It was originally hoped to be able to compare a group of recovered patients with those with persistent torticollis for such features as neuroticism, obsessional manifestations, intropunitive hostility, and marital disharmony, considered to be important factors in other studies (Meares, 1971a; Tibbetts, 1971) but the number of those in substantial remission was small at the time of the original surveys, and any comparison based on this grouping has since been invalidated by the subsequent relapse of three of the patients in this category. Evidence of neuroticism, obsessional symptoms and traits, and intropunitive hostility in the group as a whole was, therefore, assessed by comparing the group with the normal population.

Group mean scores were as follows: EPIN,9.93; Leyton Obsessional Inventory Symptom 12.03 and Trait 7.20; HDHQ Hostility 10.60 and Direction of Hostility -0.5. Separate analyses were done for males and females in the group for Leyton and HDHQ since these have separate norms for males and females. There were no significant differences between this group and the normal population. 
Sixteen of the 29 patients described factors that could have influenced the onset of torticollis or important environmental events coincident with the onset. These included, for example, exacerbation of severe marital discord, stress from a change to night shift work, an abortion, hysterectomy, and a road traffic accident in which the neck was possibly injured. The assessment of the significance of such reported events often many years later is clearly difficult.

Of the 21 married subjects, 13 were women and eight men. Marital adjustment measured on a five-point scale indicated severe or moderately severe marital discord in nine subjects, a major factor being unsatisfactory sexual adjustment.

All but six patients claimed adverse social effects from torticollis at the time of examination. Fourteen thought that, at the worst period in the course of their disorder, the disability had been severe and 11 moderately severe. Fear of ridicule and reluctance to leave the home were almost universal. Two men and one woman were too disabled to work.

\section{TREATMENT}

At the time of the original survey these patients had been subjected to a great variety of different treatments. A common pattern was that of referral by the general practitioner to a psychiatrist under the impression that spasmodic torticollis was an hysterical disorder. Eight patients had received psychiatric inpatient treatment and a further six as outpatients. Two patients had been treated with courses of electroconvulsive therapy. Another common sequence was referral from the general practitioner to an orthopaedic surgeon, perhaps because of some confusion with congenital torticollis or because it was thought that there might be some abnormality of the cervical spine. Such referral commonly led to manipulation of the neck, sometimes under anaesthesia, or immobilisation in an elaborate plaster. Reference direct to a neurologist did not lead to more successful treatment, varied forms of physiotherapy being the most popular. This ranged from local heat and exercises directed against the direction of turn to immobilisation in bed with sandbags and continuous traction. Injection of local anaesthetic into the motor point of the more accessible cervical muscles was also practised. Drug therapy included anticholinergic agents, phenothiazine derivatives, antidepressants, barbiturates, and diazepam. This last drug was frequently reported as affording some slight relief but was certainly not curative. Five patients had been treated by peripheral surgery to the muscles of the neck or their nerve supply, varying from section of one sternomastoid muscle to extensive anterior nerve root section. Three patients had been treated by stereotactic thalamotomy, but in each case treatment was limited to making a lesion on the side contralateral to the direction of turn. The only patient who was regarded as being completely cured had received treatment by hypnosis and had recovered from severe torticollis within three months. One other patient, as far as could be ascertained, had been treated in this way with only limited and temporary improvement.

At the time of the second review some patients had also received more recently developed forms of treatment including amantadine, levodopa, haloperidol, and feedback from the neck muscles, but the improvement noted in six patients was considered to be spontaneous and not related to treatment.

\section{Discussion}

Few neurologists believe spasmodic torticollis to be hysterical, and yet the evidence for organic disease remains problematical. Claims that dys- $\mathbb{D}$ tonic movements of the neck can be distinguished $\stackrel{\mathbb{D}}{\circ}$ from hysterical spasm have been based on the 0 widespread nature of the contractions, including antagonistic muscles (Herz and Glaser, 1949; Herz and Hoefer, 1949) and the combination of sustained and rhythmic activity. It is undeniable that the movement of spasmodic torticollis differs in many respects from the normal action of turning the head, but it is also possible voluntarily to effect this movement in an abnormal manner accompanied by widespread fluctuating muscular contractions. The inhibitory and enhancing effects of different forms of movement and sensory stimulation reported by Podivinsky (1968) are of great interest but are inconsistent. For example, we were unable to confirm his observations that slight touch on the side of the neck towards which the chin is turned reduces the spasm while contralateral stimulation causes enhancement. $\mathrm{He}$ also reported that supporting a weight in the ipsilateral hand aggravated the spasm in $87 \%$ of patients while using the contralateral hand reduced spasm in $78 \%$. We could find no consistent effect. The antagonistic gesture, in which sometimes a very light touch prevents the movement, has been interpreted both as an indication of reflex inhibition and of hysteria. In our test conditions spasm was more often enhanced than inhibited.

In the only thorough neuropathological examination of a patient with isolated spasmodic torticollis, adequately investigated in life, no lesion was

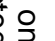


found (Tarlov, 1970). Attempts to detect a disorder of neurotransmitter mechanisms have also so far proved negative (Curzon, 1973). There is a strong association with other forms of involuntary movement, essential tremor (Couch, 1975), writer's cramp (Meares, 1971c), and torsion dystonia (Marsden and Harrison, 1974), all represented in the present series, but the anatomical basis of these conditions is also unknown. Patterson and Little (1943) reported motor abnormalities in no less than $33 \%$ of their patients including $4 \%$ with Parkinsonism. It is not easy to determine from their account how much weight should be attached to the $7 \%$ of patients who had a tremor of the hands and the $6 \%$ with masked facies. Nevertheless the association with disorders of function either certainly or probably involving the basal ganglia is impressive.

The nature of any possible underlying structural disease of the brain naturally remains obscure. It is now extremely improbable that encephalitis lethargica plays any part. Hassler and Dieckmann (1970) suggested that brain damage in infancy might be an important factor, basing this contention on asymmetry of the lateral ventricals seen on pneumoencephalography, sometimes reflected in the shape of the skull. One of our patients had a mild right infantile hemiparesis with torticollis to the right. No skull asymmetry was found in her or in the other nine patients in whom satisfactory films could be obtained.

Because of the close relationship of the vestibular system to posture of the head it has been natural to suspect that disturbance of this system might be responsible for torticollis, but there has been no systematic investigation. Detailed neurootological examination in our patients produced no evidence in support of this contention.

The approach from the psychological aspect presents similar difficulties. Paterson (1945) reported successful results from psychotherapy, but those patients whom she regarded as hysterical were not among those who recovered. Herz and Glaser (1949) considered that $50 \%$ of their patients had an abnormal personality pattern but quantitative assessment had not at that time been developed. This problem also arose with Tibbetts' (1971) recognition of an organic and a psychogenic group. Cockburn (1971) using the Maudsley personality index and other indications of premorbid stability found no difference from control subjects. Meares (1971a) also distinguished two categories. Those with greater evidence of preexisting neuroticism and psychosexual problems had a much improved chance of recovery. Both Tibbetts (1971) and Meares (1971a) thought that the type of movement also afforded evidence of causation and prognosis. It is not easy to equate their descriptive categories but both regarded sustained tonic spasm as evidence of a bad prognosis. Tibbetts thought that those with mild spasm or with irregular movements were more likely to recover while Meares emphasised the relatively good prognosis where the onset had been "jerking" or painful. Our original intention of comparing a recovered with a persistent group was thwarted by the remarkably low rate of full recovery. In the whole group no evidence of pre-existing personality disorder or neuroticism beyond that of the normal population was discovered. Clearly this method would not be capable of recognising one or two patients in whom psychological factors were indeed important or even responsible for the torticollis but our findings are further strong evidence against an hysterical cause in most patients. In those with relatively good prognosis, in that substantial or complete remission occurred at some stage of the disease, there was no important difference in the mode of onset remembered by the patient compared with the group with persistent torticollis. The exceedingly adverse effect of spasmodic torticollis on the life and happiness of many of the patients was, however, amply demonstrated.

The association between the onset of torticollis and some form of stress has been noted in other series (Paterson, 1945; Meares, 1971a). It is scarcely possible to exclude the natural tendency of the patients to associate the onset of unpleasant symptoms with physical or mental trauma. The possibility that stress might distort the pattern of neurotransmitter regulation in the central nervous system is attractive as a link between mutually exclusive "organic" and "psychogenic" disease, but remains unsubstantiated. Certainly the lack of evidence of premorbid personality disturbance is most unlike what would be expected in a conventional psychogenic disorder.

The prognosis in our patients was unexpectedly poor, only one being thought to have made a complete and lasting recovery. The tendency to relapse persisted even in those in whom spasm was regarded as minimal at the time of the initial followup examination. In general, our findings confirmed those of Meares (1971b) who recognised three stages: progression for five years, but with possibility of remission; a static stage for the next five years; and a final stage during which slight improvement might occur. This pattern is, of course, only an approximation to which many patients do not conform and, in particular, relapse may occur many years after the onset. Our study was not 
specifically concerned with treatment. In agreement with Shaw et al. (1972), we did not find that medical treatment influenced symptoms significantly, and surgery, which did not in our series include bilateral thalamotomy, was either ineffective or palliative. We found no indication of any form of curative treatment and the outcome appears to have changed little since Gowers (1893) stated that "the prognosis must be grave in every developed case."

PB would like to acknowledge the assistance of Mrs M. MacDonald in performing electronystagmography.

\section{References}

Cockburn, J. J. (1971). Spasmodic torticollis: a psychogenic condition? Journal of Psychosomatic Research, 15, 471-477.

Couch, J. R. (1975). The relationship between spasmodic torticollis and essential tremor. Transactions of the American Neurological Association, 100, 181183.

Curzon, G. (1973). Involuntary movement other than Parkinsonism. Proceedings of the Royal Society of Medicine, 66, 873-876.

Gilbert, G. J. (1971). Spasmodic torticollis healed effectively by medical means. New England Journal of Medicine, 284, 896-898.

Gowers, W. R. (1893). A Manual of Diseases of the Nervous System. Second edition, Vol. 2, p. 671. Hofner Ṕúblishing Company: Darien.

Hassler, R., and Dieckmann, G. (1970). Stereotactic treatment of different kinds of torticollis. Confinia Neurologica, 32, 135-143.

Herz, E., and Glaser, G. H. (1949). Spasmodic torticollis. II: clinical evaluation. Archives of Neurology and Psychiatry (Chicago), 61, 227-239.

Herz, E., and Hoefer, P. F. A. (1949). Spasmodic torticollis. I: physiologic analysis of involuntary motor activity. Archives of Neurology and Psychiatry (Chicago), 61, 129-136.

Hinchcliffe, R. (1968). Nystagmus rate as an index of caloric test response. Acta Otolaryngologica (Stockholm), 65, 311-315.

Jongkees, L. B. W., and Philipszoon, A. J. (1963). The caloric test in Ménières disease. Acta Otolaryngologica Scandinavica, Supplement 92, 168-170.

Marsden, C. D., and Harrison, M. J. G. (1974). Idiopathic torsion dystonia (dystonia musculorum deformans). A review of forty-two patients. Brain, 97, 793-810.

Meares, R. (1971a). Features which distinguish groups of spasmodic torticollis. Journal of Psychosomatic Research, 15, 1-11.

Meares, R. (1971b). Natural history of spasmodic torticollis and effect of surgery. Lancet, 2, 149-151.

Meares, R. (1971c). An association of spasmodic torticollis and writer's cramp. British Journal of Psychiatry, 119, 441-442.

Paterson, M. T. (1945). Spasmodic torticollis: results of psychotherapy in 21 cases. Lancet, 2, 556-559.

Patterson, R. M., and Little, S. C. (1943). Spasmodic torticollis. Journal of Nervous and Mental Diseases, 98, 571-599.

Podivinsky, F. (1968). Torticollis. In Handbook of Clinical Neurology, Vol. 6. Edited by P. J. Vinken and G. W. Bruyn. North-Holland: Amsterdam.

Shaw, K. M., Hunter, K. R., and Stern, G. M. (1972). Medical treatment of spasmodic torticollis. Lancet, 1, 1399.

Svien, H. J., and Cody, D. T. R. (1969). Treatment of spasmodic torticollis by suppression of labyrinthine activity: report of a case. Mayo Clinic Proceedings, 44, 825-827.

Tarlov, E. (1970). On the problem of the pathology of spasmodic torticollis in man. Journal of Neurology, Neurosurgery, and Psychiatry, 33, 457463.

Tibbetts, R. W. (1971). Spasmodic torticollis. Journal of Psychosomatic Research, 15, 461-469. 